\title{
PRESERVAÇÃO DA QUALIDADE PÓS-COLHEITA DE ARAÇÁ-VERMELHO ATRAVÉS DO TRATAMENTO COM 1-METILCICLOPROPENO E DO ACONDICIONAMENTO EM EMBALAGENS PLÁSTICAS, SOB REFRIGERAÇÃO ${ }^{1}$
}

\author{
CASSANDRO VIDAL TALAMINI DO AMARANTE2, \\ CRISTIANO ANDRÉ STEFFENS ${ }^{3}$, BRUNO PANSERA ESPÍNDOLA ${ }^{4}$
}

RESUMO - O objetivo deste trabalho foi estudar o padrão respiratório e de produção de etileno, e os efeitos do tratamento com diferentes doses de 1-metilciclopropeno (1-MCP) e do acondicionamento em diferentes embalagens plásticas, associado à refrigeração, na preservação da qualidade pós-colheita de araçá-vermelho. Os frutos apresentaram comportamento climatérico de respiração e produção de etileno. Frutos tratados com doses crescentes de 1-MCP $\left(0 ; 100 ; 300 ; 600\right.$ e $\left.1.200 \mathrm{~nL} \mathrm{~L}^{-1}\right)$ e armazenados a $10 \pm 1^{\circ} \mathrm{C} / 90 \pm 5 \%$ UR, durante 10 dias, apresentaram retardo substancial no amadurecimento, através da preservação da textura e inibição na mudança de cor da epiderme. Frutos acondicionados com diferentes filmes (polietileno de baixa densidade, policloreto de vinila e à base de náilon) apresentaram, em termos gerais, melhor preservação da textura e menores mudanças na cor da epiderme e perdas de massa fresca, durante armazenamento refrigerado $\left(5^{\circ} \mathrm{C}\right.$ e $10^{\circ} \mathrm{C}$ ). Os resultados demonstram que os frutos de araçá-vermelho apresentam elevada perecibilidade, caracterizada pelas elevadas taxas respiratórias e de produção de etileno, sendo mais bem preservados quando refrigerados, e tratados com 1-MCP ou acondicionados em embalagens plásticas.

Termos para indexação: Psidium cattleianum Sabine, etileno, respiração, temperatura, 1-metilciclopropeno, filmes plásticos.

\section{POSTHARVEST QUALITY PRESERVATION OF RED STRAWBERRY-GUAVAS BY TREATMENT WITH 1-METHYLCYCLOPROPENE AND FRUIT PACKAGING IN PLASTIC FILMS UNDER REFRIGERATION}

\begin{abstract}
This work was carried out to study respiration and ethylene production behavior of red strawberry-guavas and to assess the preservation of fruit postharvest quality by treatment with different doses of 1-methylcyclopropene (1-MCP) and fruit packaging in plastic films, under refrigeration. Red strawberry-guavas exhibit a climacteric behavior of respiration and ethylene production. Fruits treated with increasing doses of 1-MCP $\left(0,100,300,600\right.$, and $\left.1,200 \mathrm{~nL} \mathrm{~L}^{-1}\right)$ and stored at $10 \pm 1^{\circ} \mathrm{C} / 90 \pm 5 \% \mathrm{RH}$ for 10 days had a substantial delay in ripening, with a better retention of texture and inhibition in the change of the color of the skin. Fruits packed in different plastic films (low density polyethylene, vinyl polychloride, and nylon based films) showed, in general terms, a better retention of texture and green color of the skin, and lower mass loss during cold storage $\left(\right.$ at $5^{\circ} \mathrm{C}$ and $10^{\circ} \mathrm{C}$ ). The results showed that red strawberry-guavas are highly perishable, as a result of their high respiration and ethylene production rates. This requires immediate storage under refrigeration, and the treatment with 1-MCP or fruit packing in plastic films to preserve their postharvest quality.

Index terms: Psidium cattleianum Sabine, ethylene, respiration, temperature, 1-methylcyclopropene, plastic films.
\end{abstract}

\footnotetext{
( Trabalho 255-08). Recebido em: 03-10-2008. Aceito para publicação em: 25-04-2009.

${ }^{2}$ Ph.D., Bolsista de Produtividade em Pesquisa do CNPq, Professor do Departamento de Agronomia, Centro de Ciências Agroveterinárias (CAV), Universidade do Estado de Santa Catarina (UDESC). Av. Luiz de Camões, 2090, Caixa Postal 281, CEP 88520-000, Lages-SC. Autor para correspondência. E-mail: amarante@cav.udesc.br

${ }^{3}$ Dr., Professor do Departamento de Agronomia, CAV/UDESC, Lages-SC. E-mail: steffens@cav.udesc.br

${ }^{4}$ Acadêmico do Curso de Agronomia, Bolsista de Iniciação Científica do CNPq. CAV/UDESC, Lages-SC. E-mail: a6bp@cav.udesc.br
} 


\section{INTRODUÇÃO}

O araçá-vermelho (Psidium cattleianum Sabine) apresenta grande potencial de exploração comercial devido à coloração da epiderme, sabor acidulado e aroma peculiar. Esta espécie possui vasta dispersão territorial, ocorrendo desde os estados da região Nordeste do Brasil até a porção mais ao norte e leste do Uruguai (Marchiori \& Sobral, 1997). Seus frutos apresentam teor de antioxidantes muito superior aos frutos cítricos, que são popularmente utilizados como fonte de ácido ascórbico (Raseira \& Raseira, 1996).

O araçá-vermelho apresenta alta perecibilidade, sendo necessária a imediata refrigeração, visando a reduzir as taxas respiratórias e a preservar a qualidade pós-colheita dos frutos (Drehmer \& Amarante, 2008). Em adição a isso, outras técnicas podem ser utilizadas, como o armazenamento em condições de atmosfera controlada/modificada e o tratamento com 1-metilciclopropeno (1-MCP), inibidor da ação do etileno. Essas técnicas visam a reduzir a atividade respiratória e de produção de etileno, e a preservar os atributos de maturação, como aroma, cor, textura, acidez, sólidos solúveis, entre outros (Johnston et al., 2001; Kader, 2002; Blankenship \& Dole, 2003; Watkins, 2006).

Este trabalho teve como objetivos estudar o padrão respiratório e de produção de etileno, e avaliar os efeitos de diferentes doses de 1-MCP, bem como do acondicionamento com filmes plásticos, sob refrigeração, na preservação da qualidade pós-colheita de frutos de araçá-vermelho.

\section{MATERIAL E MÉTODOS}

Frutos de araçá-vermelho foram colhidos no final de março e início de abril de 2007, de plantas nativas localizadas no município de Lages-SC, no estádio maduro (40-60\% da superfície da epiderme com coloração vermelha).

No primeiro experimento, visando a estudar o padrão respiratório, foram feitas quantificações diárias das taxas respiratórias e de produção de etileno dos frutos armazenados em câmara BOD a $20 \pm 1^{\circ} \mathrm{C}$ e $90 \pm 5 \%$ de UR.

Para a quantificação das taxas respiratórias e de produção de etileno, os frutos foram colocados em recipientes com volume de $574,6 \mathrm{~mL}$, com fechamento hermético. Alíquotas de gás $(1 \mathrm{~mL})$ foram retiradas dos recipientes com uma seringa plástica, através de um septo, e injetadas em um cromatógrafo a gás $\operatorname{Varian}^{\circledR}$, modelo CP-3800, equipado com coluna Porapak $\mathrm{N}^{\circledR}$ de 3,0 m de comprimento (80-100mesh), metanador e detector de ionização de chama. As temperaturas da coluna, detector, metanador e injetor foram de $45^{\circ} \mathrm{C}, 120^{\circ} \mathrm{C}, 300^{\circ} \mathrm{C}$ e $110^{\circ} \mathrm{C}$, respectivamente. Os fluxos de nitrogênio, hidrogênio e ar sintético foram de 70; 30 e 300mL $\mathrm{min}^{-1}$, respectivamente. Através da diferença nas concentrações de $\mathrm{CO}_{2}$ e $\mathrm{C}_{2} \mathrm{H}_{4}$ no interior do recipiente, imediatamente após o seu fechamento e depois de 25 minutos, foram obtidas as taxas respiratórias (nmol de $\mathrm{CO}_{2} \mathrm{~kg}^{-1} \mathrm{~s}^{-1}$ ) e de produção de etileno ( $\mathrm{nmol} \mathrm{de}$ $\mathrm{C}_{2} \mathrm{H}_{4} \mathrm{~kg}^{-1} \mathrm{~s}^{-1}$ ), segundo fórmula descrita por Banks et al. (1995).

$\mathrm{O}$ experimento seguiu o delineamento inteiramente casualizado, com quatro repetições de 10 frutos.

No segundo experimento, frutos de araçávermelho foram tratados imediatamente após a colheita com 1-MCP, nas doses de $0 ; 100 ; 300 ; 600$ e $1.200 \mathrm{~nL} \mathrm{~L}^{-1}$ e armazenados em câmaras BOD, nas temperaturas de $10 \pm 1^{\circ} \mathrm{C}$ e $20 \pm 1^{\circ} \mathrm{C}$ (ambas a $90 \pm 5 \%$ de UR). As concentrações de 1-metilciclopropeno foram obtidas através do produto SmartFresh ${ }^{\circledR}$ diluído em água, com a aplicação realizada em câmaras herméticas, com volume de $1,2 \mathrm{~m}^{3}$, durante 12 horas, a $20 \pm 4^{\circ} \mathrm{C}$.

Os frutos armazenados a $10 \pm 1^{\circ} \mathrm{C}$ foram analisados na colheita e após oito e 18 dias de armazenamento quanto aos atributos de textura (força para ruptura da epiderme, força para penetração da polpa e resistência do fruto à compressão e ao corte), acidez titulável (AT), sólidos solúveis (SS) e cor da epiderme. Os frutos armazenados a $20 \pm 1^{\circ} \mathrm{C}$ foram analisados em intervalos diários quanto à cor da epiderme, em todos os tratamentos, e quanto às taxas respiratórias e de produção de etileno (conforme metodologia descrita no primeiro experimento), nos frutos-controle e tratados com 1-MCP na dose de $1.200 \mathrm{~nL} \mathrm{~L}^{-1}$.

Os atributos de textura foram analisados com um texturômetro eletrônico TAXT-plus ${ }^{\circledR}$ (Stable Micro Systems Ltda., Reino Unido). Para a quantificação da força necessária para o rompimento da epiderme e para a penetração na polpa, foi utilizada ponteira modelo PS2, com $2 \mathrm{~mm}$ de diâmetro, a qual foi introduzida na polpa a uma profundidade de $8 \mathrm{~mm}$, com velocidades pré-teste, teste e pós-teste de $10 ; 1 \mathrm{e} 10 \mathrm{~mm} \mathrm{~s}^{-1}$, respectivamente. A resistência do fruto à compressão foi determinada usando-se uma plataforma, modelo $\mathrm{P} / 75$, com $75 \mathrm{~mm}$ de diâmetro, com velocidades de pré-teste, teste e pós-teste iguais a $10 ; 0,5$ e $30 \mathrm{~mm} \mathrm{~s}^{-1}$, que exerceu uma força de compressão até uma deformação de $3 \mathrm{~mm}$ na superfície do fruto. A resistência ao corte foi efetuada utilizando uma ponteira tipo guilhotina, com velocidades de 
pré-teste, teste e pós-teste iguais a $15 ; 5$ e $30 \mathrm{~mm} \mathrm{~s}^{-1}$, com uma profundidade de corte de $20 \mathrm{~mm}$.

Os valores de AT (\% de ácido málico) foram obtidos através de uma amostra de $10 \mathrm{~mL}$ de suco extraída dos frutos, diluída com $90 \mathrm{~mL}$ de água destilada e titulada com solução de hidróxido de sódio $0,1 \mathrm{~N}$ até $\mathrm{pH} 8,1$.

Os teores de SS ( ${ }^{\circ}$ Brix) foram determinados por refratometria, utilizando-se de suco extraído conforme descrito para a AT, com correção da leitura para a temperatura de $20^{\circ} \mathrm{C}$.

A determinação da cor da epiderme foi efetuada em termos de brilho ('lightness'; $L$ ) e ângulo 'hue' $\left(h^{o}\right)$ da epiderme, com um colorímetro Minolta, modelo CR 400.

O experimento seguiu o delineamento inteiramente casualizado, com quatro repetições de 10 frutos, em ambas as temperaturas de armazenamento. Os dados foram submetidos à análise de variância e teste de comparação de médias (Tukey; $P<0,05$ ). $\mathrm{O}$ efeito de doses de 1-MCP sobre os diferentes atributos de amadurecimento, aos oito e 18 dias de armazenamento a $10 \pm 2^{\circ} \mathrm{C}$, foi analisado através de contrastes ortogonais polinomiais (linear e quadrático) aos níveis de significância de 5\%,1\% e $0,1 \%$.

No terceiro experimento, dez frutos foram acondicionados em recipientes plásticos com o volume de $310 \mathrm{~mL}$, envoltos com diferentes filmes plásticos, e armazenados em câmaras BOD, nas temperaturas de $5 \pm 1^{\circ} \mathrm{C}$ e $10 \pm 1^{\circ} \mathrm{C}$ (ambos na UR de $80-90 \%$ ) durante 11 dias. Os tratamentos utilizados foram: controle (sem filme); policloreto de vinila (PVC) com espessura de $15 \mu \mathrm{m}$; polietileno de baixa densidade (PEBD) com aditivo e $40 \mu \mathrm{m}$ de espessura; e filme à base de náilon (FN) com espessura de $20 \mu \mathrm{m}$.

Os frutos foram analisados na colheita e após 10 dias de armazenamento quanto aos atributos de textura (força para ruptura da epiderme, força para penetração da polpa e resistência do fruto à compressão e ao corte), AT, SS e cor da epiderme, conforme descrito no segundo experimento.

O experimento seguiu o delineamento inteiramente casualizado, segundo fatorial $4 \times 2$ (quatro tratamentos $\mathrm{x}$ duas temperaturas de armazenamento), com três repetições de 10 frutos. Os dados foram submetidos à análise da variância (ANOVA) e teste de comparação de médias (Tukey; $P<0,05$ ).

\section{RESULTADOS E DISCUSSÃO}

Frutos de araçá-vermelho apresentaram comportamento climatério, com picos de produção de etileno e $\mathrm{CO}_{2}$,ocorrendo cerca de 80 e 130 horas após o armazenamento a $20^{\circ} \mathrm{C}$, respectivamente (Figura 1). Frutos tratados com 1-MCP na dose de $1.200 \mathrm{~nL} \mathrm{~L}^{-1}$ apresentaram retardo no aumento das taxas de produção de etileno e de respiração em relação aos frutos-controle, durante armazenamento a $20^{\circ} \mathrm{C}$ (Figura 2). Frutos do tratamento-controle apresentaram pico de produção de etileno e de respiração aos três e quatro dias, respectivamente, quando mantidos nessa temperatura. Frutos tratados com 1-MCP somente apresentaram incremento na produção de etileno a partir do quarto dia, não sendo possível detectar o pico de produção, de etileno e aumento gradual de respiração até o $5^{\circ}$ dia.

Em frutos mantidos a $20^{\circ} \mathrm{C}$, o tratamento com 1-MCP retardou a mudança de cor da epiderme de verde para vermelha, caracterizada pela menor redução no $h^{\circ}$ (Figura 3). A dose de $100 \mathrm{~nL} \mathrm{~L}^{-1}$ apresentou pequeno efeito, sendo que doses entre $300 \mathrm{e}$ $1.200 \mathrm{~nL} \mathrm{~L}^{-1}$ foram igualmente eficientes no retardo na mudança do $h^{o}$ da epiderme.

$\mathrm{O}$ tratamento com 1-MCP também retardou o amadurecimento dos frutos armazenados sob refrigeração $\left(10^{\circ} \mathrm{C}\right)$, especialmente na avaliação feita aos 18 dias, onde apenas os atributos de SS e AT não foram afetados pelo incremento na dose de 1-MCP (Tabela 1). Na avaliação efetuada aos oito dias, houve retardo na mudança de cor da epiderme de verde para vermelha (maiores valores de $L$ e $h^{o}$ ) e no aumento dos teores de SS com o incremento nas doses de 1-MCP (efeito linear). Aos 18 dias de armazenamento refrigerado, o aumento nas doses de 1-MCP promoveu melhor preservação de todos os atributos de textura avaliados (força para ruptura da epiderme, força para penetração da polpa e resistência do fruto à compressão e ao corte) e de cor da epiderme (efeito linear).

$\mathrm{Na}$ temperatura de $10^{\circ} \mathrm{C}$, quanto maior a dose de 1-MCP maior foi o retardo na mudança de cor da epiderme (Tabela 1). O mesmo não ocorreu a $20^{\circ} \mathrm{C}$, não havendo benefícios na preservação da cor da epiderme em doses acima de $300 \mathrm{~nL} \mathrm{~L}^{-1}$ (Figura 3). Estes resultados mostram que a redução do metabolismo sob refrigeração apresenta um efeito sinérgico com 1-MCP, resultando em maior retardo na mudança de cor com o aumento nas doses do produto.

A perda de firmeza dos frutos é um dos processos da maturação mais sensíveis à ação do etileno (Lelièvre et al., 1997). O aumento nas doses de 1-MCP retardou as alterações nos atributos de textura avaliados aos 18 dias de armazenamento refrigerado (Tabela 1), devido, provavelmente, à redução da atividade das enzimas que atuam na degradação da parede celular, em resposta à inibição da ação do etileno pelo 1-MCP (Watkins, 2006; Morais et al., 
2008). O tratamento com 1-MCP também retarda a degradação de clorofilas (Blankenship \& Dole, 2003; Watkins, 2006) e reduz o acúmulo de antocianina nos frutos (Manganaris et al., 2007), inibindo assim o desenvolvimento de coloração vermelha da epiderme (Figura 3 e Tabela 1). Os atributos de qualidade relacionados aos teores de SS e AT foram menos sensíveis ao tratamento com 1-MCP durante armazenamento a $10^{\circ} \mathrm{C}$ (Tabela 1), confirmando resultados reportados por outros autores em maçãs (Fan et al., 1999; Watkins et al., 2000; Argenta et al., 2001) e pêssegos (Ligouri et al., 2004; Freitas et al., 2007) tratados com o produto.

No experimento envolvendo a utilização de diferentes filmes, a temperatura de armazenamento apresentou efeito significativo sobre diferentes atributos de amadurecimento (Tabela 2). Frutos armazenados na temperatura de $5^{\circ} \mathrm{C}$ apresentaram melhor preservação de todos os atributos de textura avaliados (força para ruptura da epiderme, força para penetração da polpa e resistência do fruto à compressão e ao corte) e da cor da epiderme, comparativamente à temperatura de $10^{\circ} \mathrm{C}$. Os teores de SS e a AT não foram afetados pela temperatura.

Em araçá-vermelho, há um aumento linear na taxa respiratória com o aumento na temperatura de armazenamento de 0 a $30^{\circ} \mathrm{C}, \operatorname{com} \mathrm{Q}_{10}=2,7$ (Drehmer \& Amarante, 2008), valor superior ao observado para a respiração, na mesma faixa de temperatura, em diversas espécies de frutos $\left(\mathrm{Q}_{10}=\right.$ 2,3) (Hardenburg et al., 1986). Desta forma, há uma grande redução na atividade metabólica dos frutos com a redução na temperatura, resultando em maior retardo no amadurecimento (Tabela 2).

$\mathrm{O}$ aumento na temperatura de armazenamento de $5^{\circ} \mathrm{C}$ para $10^{\circ} \mathrm{C}$ ocasionou maior perda de água pelos frutos apenas no tratamento-controle (Tabela 2). Neste tratamento, a elevação da temperatura, mesmo com a utilização de elevada umidade relativa (80-90\% no interior das câmaras BOD), ocasionou aumento no déficit de pressão de vapor de água (DPVA) entre o fruto e o ar da câmara, ocasionando a desidratação (Maguire et al., 2001). A utilização de filmes plásticos, independentemente do tipo, reduziu a perda de massa fresca (Tabela 2), refletindo a formação de ambiente saturado de umidade no interior da embalagem, reduzindo o DPVA e assim a transpiração (Malgarim al., 2006; Mota et al., 2006).

Considerando os filmes testados, o PEBD proporcionou melhor preservação dos atributos de firmeza relacionados à força para ruptura da epiderme, força para penetração da polpa e resistência do fruto à compressão, e menor desenvolvimento de co- loração vermelha da epiderme (maiores valores de L e $h^{\circ}$ ), comparativamente ao controle, especialmente na temperatura de $10^{\circ} \mathrm{C}$ (Tabela 2). Em frutos armazenados a $10^{\circ} \mathrm{C}$, o tratamento com PEBD apresentou também menor resistência ao corte, comparativamente ao controle, possivelmente devido à menor desidratação. A maior diferença em firmeza dos frutos embalados com PEBD, comparativamente ao controle, com a aumento da temperatura de $5^{\circ} \mathrm{C}$ para $10^{\circ} \mathrm{C}$, pode ser o resultado da maior atividade respiratória e maior modificação da atmosfera no interior da embalagem de PEBD, inibindo assim o amadurecimento (Chitarra \& Chitarra, 2005).

Em frutos armazenados na temperatura de $10^{\circ} \mathrm{C}$, o tratamento-controle apresentou, de forma geral, maiores valores de SS e AT em relação aos frutos embalados com filmes, possivelmente como reflexo da diferença na perda de massa fresca ocasionada pela desidratação. Como o tratamento-controle apresentou perda de massa fresca cerca de quatro vezes superior aos tratamentos com filmes nessa temperatura, isso pode ocasionar maior concentração de açúcares e ácidos nas células dos frutos não embalados (Calegaro et al., 2002).

De forma geral, não houve grande diferença entre os três filmes utilizados durante armazenamento a $5^{\circ} \mathrm{C}$. Todavia, na temperatura de $10^{\circ} \mathrm{C}$, o PEBD apresentou melhor desempenho, possivelmente como reflexo da sua menor permeabilidade ao $\mathrm{O}_{2}$ e $\mathrm{CO}_{2}$ em relação ao PVC e o filme à base de náilon (Chitarra \& Chitarra, 2005), promovendo assim maior modificação na atmosfera interna da embalagem e maior retardo no amadurecimento. 
TABELA 1 - Efeitos de doses de 1-MCP na preservação da qualidade pós-colheita de frutos de araçávermelho, armazenados sob refrigeração $\left(10 \pm 1^{\circ} \mathrm{C} / 90 \pm 5 \%\right.$ de UR), durante oito e 18 dias. Na colheita, os frutos apresentavam valores médios de: ângulo hue $\left(h^{\circ}\right)=47,12$; sólidos solúveis $(\mathrm{SS})=7,90^{\circ}$ Brix; e acidez titulável $(\mathrm{AT})=0,54 \%$ de ácido málico.

\begin{tabular}{|c|c|c|c|c|c|c|c|c|}
\hline \multirow{2}{*}{$\begin{array}{l}\text { Dose de } \\
\text { 1-MCP } \\
(\mathrm{ppb})\end{array}$} & \multicolumn{4}{|c|}{ Atributos de textura $(\mathrm{N})$} & \multicolumn{2}{|c|}{$\begin{array}{c}\text { Cor da } \\
\text { epiderme }\end{array}$} & \multirow[t]{2}{*}{$\begin{array}{c}\mathrm{SS} \\
\left({ }^{\circ} \mathrm{Brix}\right)\end{array}$} & \multirow{2}{*}{$\begin{array}{c}\text { AT } \\
\text { (\% ác. } \\
\text { málico) }\end{array}$} \\
\hline & $\begin{array}{c}\text { Força } \\
\text { para rup- } \\
\text { tura da } \\
\text { epiderme }\end{array}$ & $\begin{array}{c}\text { Força para } \\
\text { penetração } \\
\text { da polpa }\end{array}$ & $\begin{array}{l}\text { Resistência } \\
\text { do fruto à } \\
\text { compressão }\end{array}$ & $\begin{array}{l}\text { Resistência } \\
\text { do fruto ao } \\
\text { corte }\end{array}$ & $L$ & $h^{o}$ & & \\
\hline & \multicolumn{8}{|c|}{8 dias } \\
\hline 0 & 1,77 & 0,52 & 5,64 & 11,69 & 30,32 & 25,32 & 9,10 & 0,49 \\
\hline 100 & 1,81 & 0,50 & 5,47 & 11,90 & 29,80 & 26,66 & 9,35 & 0,51 \\
\hline 300 & 1,80 & 0,50 & 6,05 & 11,87 & 29,33 & 26,96 & 9,65 & 0,55 \\
\hline 600 & 1,90 & 0,51 & 6,14 & 14,01 & 31,59 & 30,33 & 9,30 & 0,51 \\
\hline 1.200 & 2,05 & 0,57 & 6,05 & 14,13 & 33,55 & 31,95 & 8,23 & 0,48 \\
\hline Linear & $n s$ & ns & $n s$ & $n s$ & $* *$ & $* * *$ & $*$ & $n s$ \\
\hline Quadrático & ns & ns & ns & ns & ns & $n s$ & ns & ns \\
\hline \multirow[t]{2}{*}{ C.V. (\%) } & 17,33 & 23,16 & 24,57 & 19,01 & 6,87 & 10,52 & 8,12 & 7,90 \\
\hline & \multicolumn{8}{|c|}{18 dias } \\
\hline 0 & 1,33 & 0,44 & 3,32 & 7,39 & 23,57 & 15,82 & 9,50 & 0,48 \\
\hline 100 & 1,52 & 0,49 & 3,43 & 8,38 & 23,32 & 17,27 & 9,40 & 0,54 \\
\hline 300 & 1,46 & 0,48 & 3,88 & 10,36 & 24,67 & 17,88 & 9,43 & 0,57 \\
\hline 600 & 1,59 & 0,51 & 3,70 & 9,38 & 26,33 & 19,84 & 9,15 & 0,53 \\
\hline 1.200 & 1,74 & 0,58 & 4,04 & 10,48 & 28,26 & 22,00 & 9,05 & 0,56 \\
\hline Linear & $* *$ & $* *$ & $*$ & $*$ & $* * *$ & $* * *$ & ns & ns \\
\hline Quadrático & ns & $n s$ & $n s$ & $n s$ & $n s$ & $n s$ & $n s$ & $n s$ \\
\hline C.V. (\%) & 12,63 & 13,47 & 14,97 & 19,80 & 8,12 & 13,32 & 6,29 & 9,37 \\
\hline
\end{tabular}

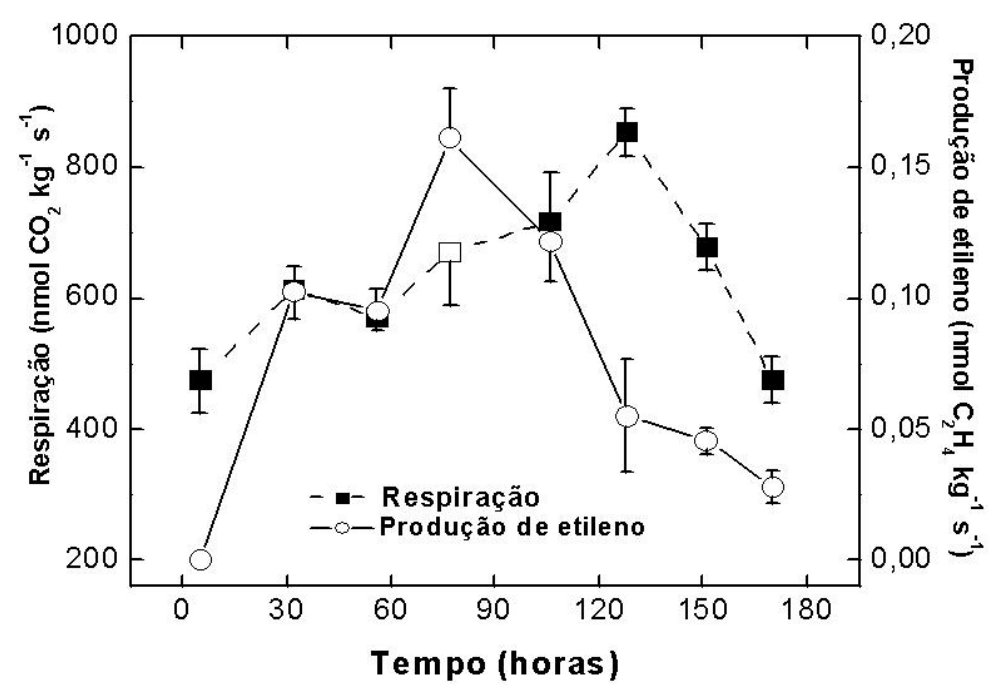

FIGURA 1- Taxas respiratórias e de produção de etileno em frutos de araçá-vermelho armazenados a $20 \pm 1^{\circ} \mathrm{C}$ e $90 \pm 5 \%$ de UR. Os símbolos representam valores médios \pm erro-padrão da média $(n=4)$. 
TABELA 2- Qualidade pós-colheita de frutos de araçá-vermelho embalados com diferentes filmes e armazenados nas temperaturas de $5^{\circ} \mathrm{C}$ e $10^{\circ} \mathrm{C}$ durante 11 dias. Na colheita, os frutos apresentavam valores médios de: ângulo hue $\left(h^{\circ}\right)=89,95$; sólidos solúveis $(\mathrm{SS})=9,13^{\circ} \mathrm{Brix}$; e acidez titulável $(\mathrm{AT})=0,59 \%$ de ácido málico.

\begin{tabular}{|c|c|c|c|c|c|c|c|c|c|}
\hline \multirow{2}{*}{ Tratamento } & \multicolumn{4}{|c|}{ Atributos de textura $(\mathrm{N})$} & \multicolumn{2}{|c|}{$\begin{array}{c}\text { Cor da } \\
\text { epiderme }\end{array}$} & \multirow{2}{*}{$\begin{array}{c}\text { SS } \\
\left({ }^{\circ} \text { Brix }\right)\end{array}$} & \multirow{2}{*}{$\begin{array}{c}\text { AT } \\
\text { (\% ác. } \\
\text { máli- } \\
\text { co) }\end{array}$} & \multirow{2}{*}{$\begin{array}{c}\text { Perda } \\
\text { de } \\
\text { massa } \\
\text { fresca } \\
(\%)\end{array}$} \\
\hline & $\begin{array}{l}\text { Força para } \\
\text { ruptura da } \\
\text { epiderme }\end{array}$ & $\begin{array}{c}\text { Força para } \\
\text { penetração } \\
\text { da polpa }\end{array}$ & $\begin{array}{c}\text { Resistência } \\
\text { do fruto à } \\
\text { compressão }\end{array}$ & $\begin{array}{l}\text { Resistência } \\
\text { do fruto ao } \\
\text { corte }\end{array}$ & $L$ & $h^{o}$ & & & \\
\hline Controle & \multicolumn{6}{|c|}{$5^{\circ} \mathrm{C}$} & $9,2 \mathrm{a}$ & $0,51 \mathrm{a}$ & $8,0 \mathrm{a}$ \\
\hline $\mathrm{FN}^{*}$ & $1,49 \mathrm{ab}$ & $0,40 \mathrm{ab}$ & $4,08 \mathrm{ab}$ & $11,44 \mathrm{a}$ & $37,2 \mathrm{a}$ & 33,7 a & $9,2 \mathrm{a}$ & $0,48 \mathrm{a}$ & $2,8 \mathrm{~b}$ \\
\hline PEBD $^{* *}$ & $1,57 \mathrm{ab}$ & $0,42 \mathrm{a}$ & $5,88 \mathrm{a}$ & $10,00 \mathrm{a}$ & $38,3 \mathrm{a}$ & $33,1 \mathrm{a}$ & $8,9 \mathrm{a}$ & $0,54 \mathrm{a}$ & $3,1 \mathrm{~b}$ \\
\hline $\mathrm{PVC}^{* * *}$ & $1,60 \mathrm{a}$ & $0,46 \mathrm{a}$ & $4,37 \mathrm{a}$ & $10,57 \mathrm{a}$ & $33,9 \mathrm{~b}$ & $28,2 \mathrm{~b}$ & $8,8 \mathrm{a}$ & $0,52 \mathrm{a}$ & $3,4 \mathrm{~b}$ \\
\hline Média & $1,53 \mathrm{~A}$ & $0,40 \mathrm{~A}$ & $4,17 \mathrm{~A}$ & $10,69 A$ & $35,8 \mathrm{~A}$ & 30,7 A & $9,0 \mathrm{~A}$ & $0,51 A$ & 4,3 B \\
\hline \multirow[t]{2}{*}{ C.V. (\%) } & 5,0 & 19,9 & 38,1 & 8,2 & 6,5 & 10,5 & 3,1 & 8,92 & 57,2 \\
\hline & \multicolumn{9}{|c|}{$10^{\circ} \mathrm{C}$} \\
\hline Controle & $1,24 \mathrm{~b}$ & $0,25 \mathrm{c}$ & $1,01 \mathrm{c}$ & $9,97 \mathrm{a}$ & $30,4 \mathrm{~b}$ & $28,2 \mathrm{~b}$ & $9,4 \mathrm{a}$ & $0,59 \mathrm{a}$ & $13,5 \mathrm{a}$ \\
\hline FN & $1,25 \mathrm{~b}$ & $0,37 \mathrm{~b}$ & $3,63 \mathrm{~b}$ & $8,67 \mathrm{~b}$ & $26,8 \mathrm{c}$ & $21,2 \mathrm{c}$ & $8,9 \mathrm{ab}$ & $0,54 \mathrm{~b}$ & $2,7 \mathrm{~b}$ \\
\hline PEBD & $1,54 \mathrm{a}$ & $0,45 \mathrm{a}$ & $5,82 \mathrm{a}$ & $8,45 \mathrm{~b}$ & $44,1 \mathrm{a}$ & $45,1 \mathrm{a}$ & $8,2 \mathrm{~b}$ & $0,45 \mathrm{c}$ & $3,3 \mathrm{~b}$ \\
\hline PVC & $1,32 \mathrm{~b}$ & $0,36 \mathrm{~b}$ & $3,64 \mathrm{~b}$ & $9,35 \mathrm{ab}$ & $29,1 \mathrm{bc}$ & $20,6 \mathrm{c}$ & $8,5 \mathrm{~b}$ & $0,43 \mathrm{c}$ & $3,4 \mathrm{~b}$ \\
\hline Média & $1,34 B$ & $0,36 B$ & $3,58 \mathrm{~A}$ & $9,11 B$ & $32,6 \mathrm{~B}$ & $28,8 B$ & $8,7 \mathrm{~A}$ & $0,50 \mathrm{~A}$ & $5,8 A$ \\
\hline C.V. (\%) & 9,8 & 21,9 & 25,9 & 9,4 & 21,9 & 36,0 & 7,0 & 13,63 & 62,2 \\
\hline
\end{tabular}

* FN=filme à base de náilon; ** $\mathrm{PEBD}=$ polietileno de baixa densidade; $\mathrm{e} * * * \mathrm{PVC}=$ policloreto de vinila. Médias nas colunas seguidas de mesma letra, minúsculas para comparação entre tratamentos com filmes plásticos na mesma temperatura, e maiúsculas para comparação entre temperaturas de armazenamento, não diferem entre si, pelo teste de Tukey $(P<0,05)$.
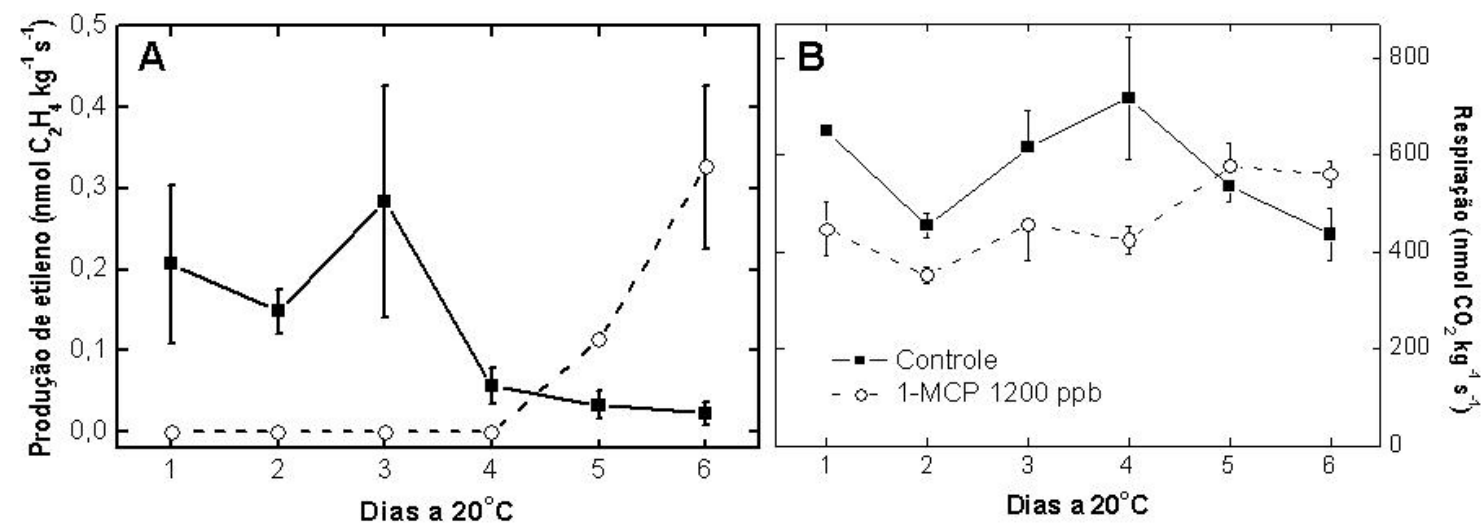

FIGURA 2- Taxas de produção de etileno (A) e de respiração (B) em frutos de araçá-vermelho, tratados ou não com 1-MCP na dose de $1.200 \mathrm{~nL} \mathrm{~L}^{-1}$ e mantidos a $20 \pm 1^{\circ} \mathrm{C}$ e $90 \pm 5 \%$ de UR. Os símbolos representam valores médios \pm erro-padrão da média $(n=4)$. 


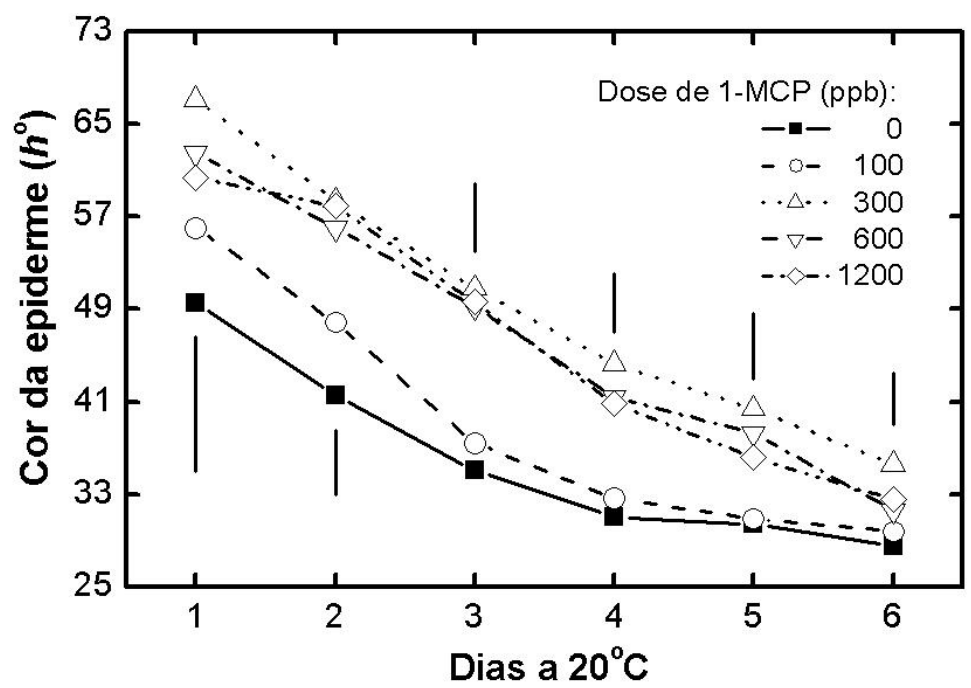

FIGURA 3- Cor da epiderme (ângulo 'hue'; $h^{\circ}$ ) em frutos de araçá-vermelho tratados com diferentes doses de 1 -MCP e mantidos a $20 \pm 1{ }^{\circ} \mathrm{C}$ e $90 \pm 5 \%$ de UR. Diferenças mínimas significativas entre tratamentos, em cada data de avaliação, indicadas pelas barras verticais, que foram calculadas pelo teste de Tukey $(\mathrm{P}<0,05)$.

\section{CONCLUSÕES}

1- Os frutos de araçá-vermelho apresentam comportamento climatérico.

2- $\mathrm{O}$ tratamento com 1-MCP reduz as taxas respiratórias e de produção de etileno e retarda a maturação dos frutos.

3- $\mathrm{O}$ uso combinado da refrigeração $\left(5^{\circ} \mathrm{C}\right)$ e filme plástico preserva a qualidade pós-colheita dos frutos.

\section{REFERÊNCIAS}

ARGENTA, L.C.; MATTHEIS, J.; FAN, X. Retardamento da maturação de maçãs 'Fuji' pelo tratamento com 1-MCP e manejo da temperatura. Revista Brasileira de Fruticultura, Jaboticabal, v.23, n.2, p.270-273, 2001.

BANKS, N.H.; CLELAND, D.J.; CAMERON, A.C.; BEANDRY, R.M; KADER, A.A. Proposal for a rationalized system of units for postharvest research in gas exchange. HortScience, Alexandria, v.30, n.6, p.1129-1131, 1995.

BLANKENSHIP, S.M.; DOLE, J.M. 1-Methylcyclopropene: a review. Postharvest Biology and Technology, Amsterdam, v.28, n.1, p.1-25, 2003.
CALEGARO, J.M.; PEZZI, E.; BENDER, R.J. Utilização de atmosfera modificada na conservação de morangos em pós-colheita. Pesquisa Agropecuária Brasileira, Brasília, v.37, n.8, p.1049-1055, 2002.

CHITARRA, M.I.F.; CHITARRA, A.B. Pós-colheita de frutas e hortaliças. Lavras: Editora UFLA, 2005. 785 p.

DREHMER, A.M.F.; AMARANTE, C.V.T. do. Conservação pós-colheita de frutos de araçá-vermelho em função do estádio de maturação e temperatura de armazenamento. Revista Brasileira de Fruticultura, Jaboticabal, v. 30, n. 2, p. 322-326, 2008.

FAN, X.T.; BLANKENSHIP, S.M.; MATTHEIS, J.P. 1-Methylcyclopropene inhibits apple ripening. Journal of American Society of Horticultural Science, Alexandria, v.124, n.6, p.690-695, 1999.

FREITAS, S.T. de; SAUTTER, C.; SILVEIRA, A.C.; BRACKMANN, A. Evaluacion del efecto de la aplicacion de 1-MCP y la conservacion en atmosfera controlada sobre la calidad poscosecha de duraznos en dos estados de madurez. Agrociencia Montevideo, Montevideo, v.11, n.1, p.67-72, 2007.

HARDENBURG, R.E.; WATADA, A.E.; WANG, C.Y. The commercial storage of fruits, vegetables and florist and nursery stocks. Washington: Department of Agriculture, Agricultural Research Service, 1986. 136p. (Agricultural Handbook, 66). 
JOHNSTON, J.W.; HEWETT, E.W.; HERTOG, M.L.A.T.M.; HARKER, F.R. Temperature induces differential softening responses in apple cultivars. Postharvest Biology and Technology, Amsterdam, v.23, n.3, p.185-196, 2001.

KADER, A.A. Postharvest technology of horticultural products. $3^{\text {nd }}$ ed. Oakland: University of California, 2002. $535 \mathrm{p}$.

LELIÈVRE, J.M.; LATCHÉ, A.; JONES, B.; BOUZAYEN, M.; PECH, J.Z. Ethylene and fruit ripening. Physiologia Plantarum, Lund, v. 101, n.4, p. 727-739, 1997.

LIGOURI, G.; WEKSLER, A.; ZUTAHI, Y.; LURIE, S.; KOSTO, I. Effect of 1-methylcyclopropene on ripening of melting flesh peaches and nectarines. Postharvest Biology and Technology, Amsterdam, v.31, n.3, p.263-268, 2004.

MAGUIRE, K.M.; BANKS, N.H.; OPARA, L.U. Factors affecting weight loss of apples. Horticultural Reviews, New York, v.25, p.197-234, 2001.

MALGARIM, B.M.; CANTILLANO, R.F.F.; TREPTOW, R.O.; SOUZA, E.D.; COUTINHO, E.F. Modificação da atmosfera na qualidade pós-colheita de ameixas cv. Reubennel. Revista Brasileira de Fruticultura, Jaboticabal, v.27, n.3, p.373-378, 2006.

MANGANARIS, G.A.; VICENTE, A.R.; CRISOSTO, C.H.; LABAVITCH, J.M. Effect of dips in a 1-methylcyclopropene-generating solution on 'Harrow Sun' plums stored under different temperature regimes. Journal of Agricultural and Food Chemistry, Davis, v.55, n.17, p.7015-7020, 2007.
MARCHIORI, J.N.C.; SOBRAL, M. Dendrologia das angiospermas: Myrtales. Santa Maria: UFSM, 1997. 100p.

MORAIS, P.L.D. de; LIMA, L.C. de O.; MIRANDA, M.R.A. de; ALVES, J.D.; ALVES, R.E.; SILVA, J.D. Enzyme activities and pectin breakdown of sapodilla submitted to 1-methylcyclopropene. Pesquisa Agropecuária Brasileira, Brasília, v.43, n.1, p.15-20, 2008.

MOTA, W.F. da; SALOMÃO, L.C.C.; NERES, C.R.L.; MIZOBUTSI, G.P.; NEVES, L.L. de M. Uso de cera de carnaúba e saco plástico poliolefínico na conservação pós-colheita do maracujá-amarelo. Revista Brasileira de Fruticultura, Jaboticabal, v.28, n.2, p.190-193, 2006.

RASEIRA, M.C.B.; RASEIRA, A. Contribuição ao estudo do araçazeiro (Psidium cattleyanum). Pelotas: EMBRAPA/CPACT, 1996. 95p.

WATKINS, C.B.; NOCK, J.F.; WHITAKER, B.D. Response of early, mid and late season apple cultivars to postharvest application of 1-methylcyclopropene (1-MCP) under air and controlled atmosphere storage conditions. Postharvest Biology and Technology, Amsterdam, v.19, n.1, p.17-32, 2000.

WATKINS, C.B. The use of 1-methylcyclopropene (1-MCP) on fruits and vegetables. Biotechnology Advances, Amsterdam, v.24, n.4, p.389-409, 2006. 